\title{
Knowledge and practice of menstrual hygiene among the girls in Janapriya Multiple Campus, Pokhara
}

\author{
Krishna Prasad Tripathi \\ Department of HPPE, Prithvi Narayan Campus, TU, Pokhara, Nepal \\ Corresponding Author \& Email \\ Krishna Prasad Tripathi; Email: krishnatripathi59@gmail.com
}

Article History

Submitted 21 December 2021; Reviewed 31 December 2021; Accepted 09 January 2022 DOI: https://doi.org/10.3126/ajps.v1i1.43597

\section{Copyright Information: \\ Copyright 2022@ The Author(s). \\ The journal is licensed under a \\ Creative Commons Attribution- \\ ShareAlike 4.0 International \\ License. \\ (c) (i) (2) \\ Published by \\ Department of Population Studies \\ Prithvi Narayan Campus \\ Tribhuvan University \\ Pokhara, Nepal}

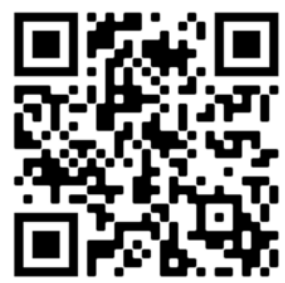

Scan to Access eJournal

\section{Abstract}

This study is carried out to identify the knowledge and practice of menstrual hygiene among girl students studying in Janapriya Multiple Campus (JMC). A descriptive and analytical study design is used to assess the knowledge and practice of girl students of JMC. All the female students were the population and the sample size was 111 from 10 plus two level and bachelor level randomly. The quantitative data collected was analysed using SPSS for Windows version 16.0. Bi-variable analysis was carried out to identify factors related to the practice of menstruation and menstrual hygiene. There is no significant association between caste and use of absorbent (chi-square $=$ 1.84 with a degree of freedom $=1$ and $p>0.05$.). The majority had knowledge about the use of sanitary pads; however, a small proportion (15\%) of them used old cloths and reused those clothes after washing again. One or more cultural taboos and restrictions were practiced related to menstruation. More than half of the respondents had the problem of performing religious rites, followed by those having problem of entry into the kitchen and were not allowed to use the same bed. However, a few (5.4\%) had no problems at their homes. It was concluded that traditional taboos were still seen in the communities from where the students came. So, reproductive health related awareness programme should be launched on those communities.

Keywords: Absorbent, disposal of pads, management of sanitary napkin, menstruation hygiene 


\section{Knowledge and Practice of Menstrual Hygiene among the Girls}

\section{Introduction}

Menstruation is the natural process of growing, eating and excretion. However, in many parts of the world, it remains taboo and there are many myths. Menstrual hygiene is one of the important factors of women's reproductive health. But there were various cultural taboos and socio-cultural restrictions in Nepal. These taboos and cultural restriction result in adverse health effects in adolescent girls. Lawan, Yusuf, \& Musa (2010) said that menstruation is the periodic vaginal bleeding that occurs in puberty. Every mature female menstruates on average 3-5 days each month until menopause.

Menstrual cycles sometimes bring a variety of painful symptoms for some girls and some women during the menstruation period. There might be premenstrual syndrome (PMS) before one to two weeks of starting menstruation. It includes mild cramping, irritability, headache, backaches, breast soreness, constipation or diarrhoea and fatigue, but the symptoms usually go away when the period begins. An abnormal menstrual cycle includes early or late menstruation. The average menstrual cycle lasts 28 days. If the period occurs before 21 days or more than 35 days apart is called abnormal menstruation. Heavy or too light bleeding during the period is also called abnormal menstruation. Serious menstrual problems are heavy bleeding for five to seven days. It is also called Menorrhagia. Heavy and irregular menstruation may cause due to puberty, vaginal infection, hypothyroidism, change in diet and exercise absent period is seen in some girls. If the period is not seen till 16 years, it is called Amenorrhea. Some women experience excursing pain which is called Dysmenorrhea. It may be due to fibroids, pelvic inflammation disease, and abnormal tissue growth outside the uterus and so on (Moore, 2020). Some women experience a range of physical and emotional symptoms. Others experience few symptoms or even none at all.

Menstruation is a normal physiological process of females. Although it is a sign of their reproductive capacity, it is surrounded by social taboos and supernatural beliefs. The poor knowledge and understanding of menstruation may lead to unsafe hygienic practice that intern increases the risk of reproductive and genital urinary tract infections, cervical cancer, school drop-out, poor academic performance and overall poor quality of life. Despite such clinical and academic effects, the knowledge and hygienic practice of adolescent girls towards menstruation is not well addressed in Ethiopia, particularly among school adolescent girls (Lawan, Yusuf \& Musa, 2010). Menstrual hygiene is important to reduce vulnerability to reproductive tract infections (RTI) (Singh, 2001). Menstrual hygiene is taking care of the sanitary condition of the vulva. This should be done by using sanitary pads instead of dirty rags which are commonly used by a less privileged class of women (Teluram, 1978). The researchers had the curiosity to find out the practice of using sanitary pads or rags.

Wash United (2020) is a non-profit German international organization that was established in 2013.It coordinates overall global Menstrual Hygiene. May 28 is the Menstrual Hygiene Day. 'It is the platform that brings together the voices and promotes good Menstrual Hygiene Management (MHM) for all women and girls'. On that day, menstrual hygiene related materials are distributed on the leadership of wash united'. Those materials included the ones that catch the menstrual flow, such as cloths, reusable and disposable pads, menstrual cups and tampons. Menstrual supplies are other supportive items for menstrual hygiene which are soap, underwear and pain relief'. Poor menstrual hygiene is caused by many reasons like lack of education, continuing restrictions and stigma, limited access to menstrual supplies and poor sanitation. As a result, millions of women and girls are kept from reaching their full potential (Wash United, 2020). So the schools need to provide sanitary pads as well as menstrual supplies 


\section{Knowledge and Practice of Menstrual Hygiene among the Girls}

to the girl students with the cooperation of many organizations which are working on menstrual hygiene.

Menstruation is a natural and biological phenomenon in females. Various gynaecological problems can be seen in the reproductive life of girls due to poor personal hygiene (Kamath, Ghosh, Lena, \& Chandrasekaran, 2013). Adolescent girls of Nepal faced many socio cultural restrictions and taboos. These result in adverse health outcomes in many Nepalese societies (Bhusal, 2020).

The majority of college girls in Nepal can be assumed to have knowledge regarding menstruation and menstrual hygiene because they study on these topics from grade six to twelve. However, despite the bins available for the disposing, many instances have been found of girls throwing sanitary pads in the toilet pan, which caused blockade. Witnessing such incidents made the researcher to have some insight on the gap between knowledge and practice of menstrual hygiene among the college girls.

\section{Figure 1}

Factors associated with knowledge and practice of menstruation practice

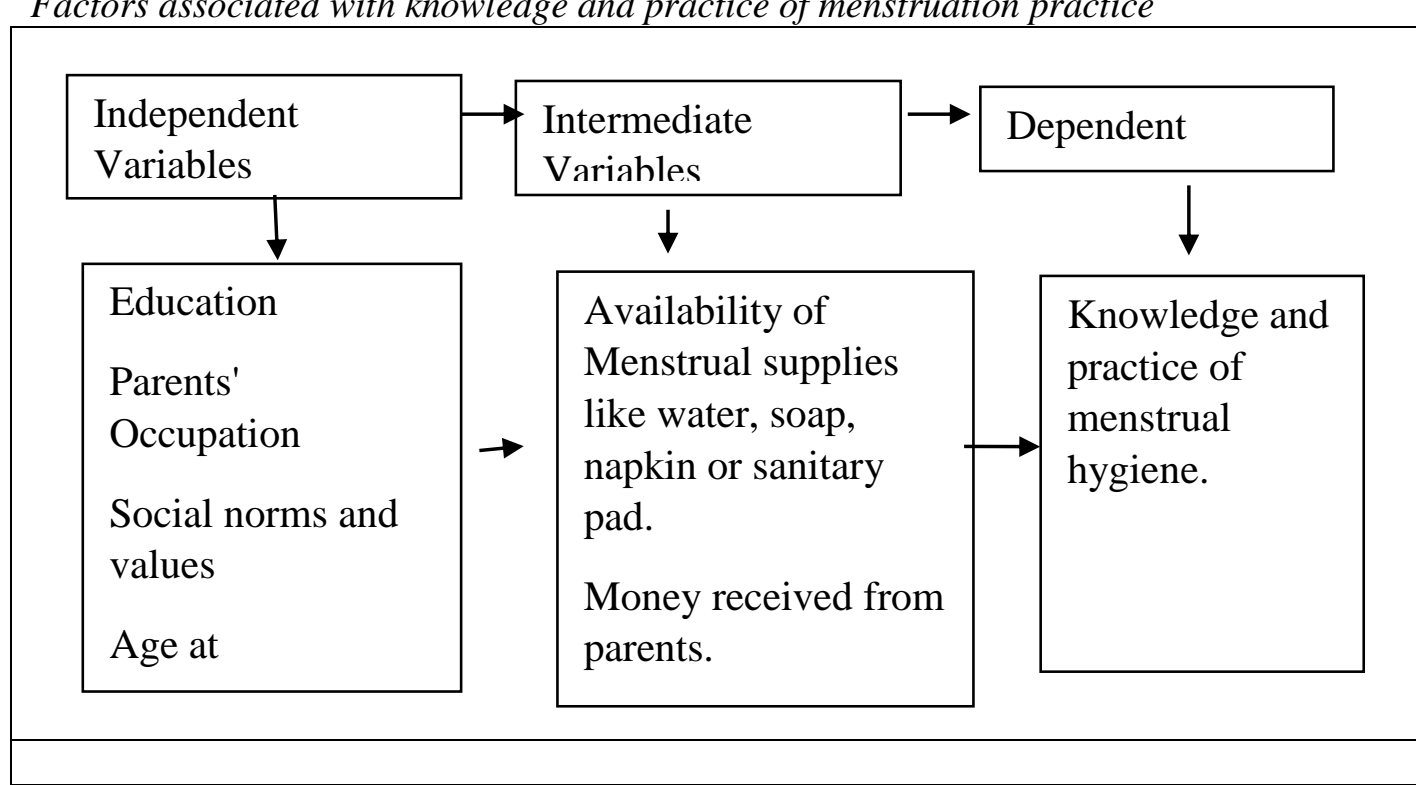

This conceptual framework showed the relation among the variables.

The objectives were as:

i. To identify the knowledge and practice on menstrual hygiene among JMC girl students.

ii. To highlight the socio-cultural beliefs associated with menstruation

\section{Data and Methods}

This study is based on the explanatory sequential design, using a mixed-method. An interview schedule with structured questions was used to obtain necessary data. The availability of the menstrual supplies in the campus was observed to ensure the logistic provision on menstrual hygiene of the students in the campus. All the female students enrolled in JMC were considered the population of the study. Multi-stage sampling techniques had been used. JMC was selected through the convenience sampling method. Academic levels (10+2 and Bachelor) were selected as their class running at that survey time. Class or sections were selected randomly. The girl students from the two academic 


\section{Knowledge and Practice of Menstrual Hygiene among the Girls}

levels and sections, who were willing to provide information, were selected as the sample through census. Altogether, the sample size was 111 from both levels. Selected girl students were provided with the questionnaire and requested to fill up the questionnaire. Qualitative data were obtained from the observation of the vendor machine, restrooms and the other menstrual supplies within the campus premises.

The major tools of data collection were questionnaires and checklists which were pretested in a similar and neighbouring college La Grande international college. The researcher had been teaching Health and Physical Education in JMC so it was convenient to obtain data. Data were entered, reviewed and computed using the Statistical Process of Social Science (SPSS) version 16 to calculate the frequency and percentage. The necessary comparison was done with other researchers' findings and conclusions. Voluntary participation, secrecy, and confidentiality were strictly followed. Each participant was informed about the purpose and value of the study. Informed consent was obtained from each participant. Personal identifiers were not recorded to keep confidentiality. The information was coded and kept confidential.

\section{Results and Discussion}

Personal hygiene involves those practices made by an individual to care for one's cleanliness of clothes and body. Personal hygiene practice improves personal health, curing of personal illness, maintains optimal health and social acceptance. Proper personal hygiene can be cultural-specific as well and may change over time. Bathing daily, washing hands, washing scalp, keeping hair short, wearing clean clothes, trimming nails, brushing teeth, proper sleep and rest are the essential menstrual hygiene.

From the data, it was seen that more than two-third 79.3 per cent of girls had their first menstruation at the ages of 11-14 years. Data indicates that more than three quarters 77.5 used sanitary pads as the ideal absorbent. Similarly, 15.5 per cent used reusable cloth 68 per cent used sanitary pads only. The person who used those reusable clothes faced problems in maintaining privacy while washing and drying those clothes. Some women or girls dried and stored those washing rags in unhygienic places like the dark corner inside the room or bathroom or outside the corner which sometimes causes infections. Most of the respondents 82.9 per cent put the pad in a dustbin. Only 3.6 per cent threw pads as the other waste in the sack or delivery bag, similar per cent burying in their backyard, 8.1 per cent wrapped in delivery bags. More than one-third of respondents changed sanitary pads whenever it wets. More than one quarter 28.8 per cent changed it thrice a day, 27 per cent changed twice a day. Only 6.3 changed once a day. Similarly, respondents were asked about their bathing. More than half (55\%) mentioned that they had to bathe on the third day. Nearly one third (32.4\%) said they had to bathe daily, followed by those who bathe on the first day (11.7\%).

\section{General and Demographic Information of Respondents}

Menstruation is the natural process of normal womanhood. Jones and Bartlett (2015) wrote that the first menstruation was seen between 10 and 15 years old. The average age is 12 , but every girl's body has its own schedule (p. 94.) although there is no such a right age for a girl to get her period. Table 1 shows their age of menstruation in the study college.

Table 1

Onset of Menstruation

\begin{tabular}{ccc}
\hline Onset Of Menstruation (Years) & Frequency & Per cent \\
\hline 11 & 4 & 3.6 \\
12 & 12 & 10.8
\end{tabular}




\section{Knowledge and Practice of Menstrual Hygiene among the Girls}

$\begin{array}{ccc}13 & 36 & 32.4 \\ 14 & 36 & 32.4 \\ 15 & 18 & 16.2 \\ 16 & 3 & 2.7 \\ 17 & 2 & 1.8 \\ \text { Total } & 111 & 100.0\end{array}$

Table 1 shows the age at onset of menstruation among the respondents. Nearly one third girls 32.4 per cent had menarche at the age of 13 and similar proportion had menarche at the age of 14 . Similarly, 16.2 per cent had menarche at the age of 15 . Only 4.5 per cent had late menarche and only 3.6 per cent had early means that is to say at the age of 11 . Menarche prior to the age of 12 and 15 years onwards is generally referred to as early and late means respectively. "The average age for a girl to get her first period in the US is 12 , but the range of age is about 8 to 15 years old. Women usually have periods until about ages 45 to 55" (Davis, 2019). It was seen that more than 80 per cent had first menstruation up to 14 years.

From the data it was found that both Hindu and Buddhists had first means at the age of 11 years. Similarly, Hindu girls had first menstruation with in the age of 15 . All Muslim girls in the sample had first means at the age of 13. Only girls had Amenorrhea whose menstruation period is seen after 16 years or they had first means at the age of 17 . All the girls had menstruation from the age of 11 to 17 . But there was no any significance between the first menstruation and religion. Majhi (2016) made a research in Bangladesh and found that 59.0 per cent of girls had first menstruation between the ages of 12-13 years.

From the study it was found that 69.4 per cent lived in nuclear family and 30.6 lived in joint family. Nuclear family girl had earlier first menstruation than the joint family. Occupation is one of the main things which lead the people physically or mentally active. Occupation refers to any work which is applied for the condition of their life. Economic and using sanitary thing are closely interlinked, one reinforcing the other. Occupation decides the living standard of the people. It was believed that economically sound girls had the more chance to use sanitary things rather than poor economic background. Table 2 shows that the sources of income in family.

Table 2

Sources of Income in Family

\begin{tabular}{ccc}
\hline Sources of Income in Family & Frequency & Per cent \\
\hline Agriculture & 33 & 29.7 \\
Job & 42 & 37.8 \\
Labour & 12 & 10.8 \\
Business & 16 & 14.4 \\
Others & 8 & 7.2 \\
Total & 111 & 100.0 \\
\hline
\end{tabular}

Table 2 shows that more than one quarter 29.7 per cent parents had the profession of agriculture. More than one-third of the respondent's parents had jobs either government or private. Similarly, 10.8 per cent of respondents' parents had outside the country as the labour. From the observation, it was found that sanitary pad from the market was bought by those who had money with them and low-income students mainly used napkin from the vendor machine fixed outside the girl's restroom. The caste system still exists in Nepal. There was 18 per cent Brahmin, 22.5 per cent Chhetry, 27 per cent Janajati and14.5 per cent Dalit students were studying there. Education is one of the prominent social factors which represent the reproductive behaviour of women. To know 


\section{Knowledge and Practice of Menstrual Hygiene among the Girls}

about the educational characteristics of the respondents it is most necessary to collect information about the educational attainment of the study population for this purpose questionnaires were administered to the respondents to know about educational attainment, plus two level or bachelor level. The researcher took 60 per cent respondents from plus two level and forty per cent from the bachelor level. Bachelor level respondents were found to have more knowledge and practice on menstrual hygiene.

\section{Menstrual Knowledge and Practice}

Davis (2019) said that menstruation is a normal process for females. It was the body's preparation for potential pregnancy in ladies. It occurs in the female reproductive organs that make pregnancy possible. Medically, it is the process in a woman of discharging blood and other materials from the uterus at about a month interval from puberty to menopause except during pregnancy. This discharging process lasts about 3-5 days. Every woman had different feelings during the period. Respondents were asked what they were feeling during their first menstruation time.

Table 3

Feeling during menstruation

\begin{tabular}{ccc}
\hline Feeling on Menstruation & Frequency & Per cent \\
\hline Happy & 7 & 6.3 \\
Sad & 29 & 26.1 \\
Frightened & 18 & 16.2 \\
Confused & 31 & 27.9 \\
Normal & 18 & 16.2 \\
Shyness & 8 & 7.2 \\
Total & 111 & 100.0 \\
\hline
\end{tabular}

Feeling is the mental process of thinking about something. Table 3 demonstrates that more than one-quarter of respondents 27.9 per cent felt confused and 26.1 felt sad. Only seven respondents out of 111 felt happy when they had first means. Only 16.2 per cent felt normal on it. Only 22.5 had positive feelings about it but on the other hand, others felt sad, frightened, confused, and shy. This shows the attitude and feeling of society on the means which impacts their daughters. Majhi (2016) found that 44 per cent and 29 per cent of respondents were respectively upset and tensed during their first menstruation. Respondents were asked whether they used absorbent or not. Almost 96.4 per cent said they used absorbents. Only one respondent out of 111 did not respond to it. Just 2.7 per cent said they did not use any absorbents.

There is no significant association between caste and use of absorbent (chisquare $=4.52$ with a degree of freedom $=3$ and $\mathrm{p}>0.05$.). All the students were in a homogenous group of college students who had a similar status as well as similar educational status as a result the researcher could not find the association between caste and use of absorbent. Similarly, the researcher wanted to see the association between absorbent and family type.

Table 4

Use of Absorbent by Type of Family

\begin{tabular}{|c|c|c|c|c|c|c|}
\hline \multirow{3}{*}{ Use of Absorbent } & \multicolumn{4}{|c|}{ Family Type } & \multirow{2}{*}{\multicolumn{2}{|c|}{ Total }} \\
\hline & \multicolumn{2}{|c|}{ Nuclear } & \multicolumn{2}{|c|}{ Joint } & & \\
\hline & $\mathrm{n}$ & $\%$ & $\mathrm{n}$ & $\%$ & $\mathrm{n}$ & $\%$ \\
\hline Yes & 76 & 70.4 & 32 & 29.6 & 108 & 100.0 \\
\hline
\end{tabular}

Asian Journal of Population Sciences [Volume 1, 15 January 2022, pp. 66-76] 


\section{Knowledge and Practice of Menstrual Hygiene among the Girls}

$\begin{array}{ccccccc}\text { No } & 1 & 33.3 & 2 & 66.7 & 3 & 100.0 \\ \text { Total } & 77 & 69.4 & 34 & 30.6 & 111 & 100.0\end{array}$

There is no significant association between family type and use of absorbent (chi-square $=1.84$ with a degree of freedom $=1$ and $p>0.05$.). College students were in a homogenous group so the family type and use of absorbent had no significant association. The researcher tried to find the ideal absorbent of those students.

Table 5

Ideal Absorbent as perceived by the respondents

\begin{tabular}{ccc}
\hline Ideal Absorbent & Frequency & Per cent \\
\hline Sanitary Pad & 86 & 78.1 \\
Reusable Cloth & 17 & 15.4 \\
Reusable Tampons of Cotton & 3 & 2.7 \\
Menstrual cup & 1 & .9 \\
Sanitary Napkins & 2 & 1.8 \\
Sea Sponge Tampons & 1 & .9 \\
Total & 110 & 100 \\
\hline
\end{tabular}

Table 5 indicates that more than three quarters 78.1 used a sanitary pad as the ideal absorbent. Similarly, 15.4 used reusable cloth. Only 2.7 used reusable Tampons of cotton, 1.8 used sanitary napkins and only one used a menstrual cup, sea sponge tampons. One respondent was missing from the answer. Similarly, they were asked what the methods of disposing of those sanitary pads were. Majhi (2016) made research in Bangladesh and found that more than 68 per cent used sanitary pads only. Nearly one third 32 per cent used old cloths as sanitary pads. Most of them reused those cloths or rags after washing. They faced problems to make wet because they felt say to show outside the sun. Some females dry and store those cloths in unhygienic places like inside the corner of the bathroom which sometimes causes infections too.

Table 6

Methods of Disposal

\begin{tabular}{ccc}
\hline Methods of Disposal & Frequency & Per cent \\
\hline Putting in a dustbin & 92 & 83.6 \\
Throwing as other waste & 4 & 3.6 \\
Burying at a proper place & 4 & 3.6 \\
Flushing in the toilet & 1 & .9 \\
Wrapping in a delivery bag & 9 & 8.1 \\
Total & 110 & 100 \\
\hline
\end{tabular}

Table 6 displays that 83.6 per cent respondents disposed the used pads in a dustbin. Only 3.6 per cent threw pads as the other waste in the sack or delivery bag, similar proportion buried at their backyard as proper places to dispose, 8.1 per cent wrapped in the delivery bags. One girl did not respond to the question regarding the disposal of the used pads. Majhi (2016) found that 75 per cent of adolescent girls disposed of the used pads in ponds. One-quarter of them disposed of usual home garbage. Only 2 per cent of them burnt it. Respondents were asked whether there was a facility for dustbin, soap and water in the college.

Most of the respondents 95.5 per cent told that the campus managed the facilities. The rest said no available there. Half of the respondents (50.5\%) told that they used the napkin pad from the vendor of JMC. Others managed from the home or some used clean clothes as the absorbent. Nearly two-third 64.9 per cent told that the process 


\section{Knowledge and Practice of Menstrual Hygiene among the Girls}

of getting paid from the vendor of JMC is student-friendly. Nearly one quarter 23.4 per cent said it was not student-friendly. Those who said it was not student-friendly asked how it could make student-friendly. They said that those pads were kept in open access and need to carry as like just condoms in the hospital. But the campus could not put such a pad in such away. Students carried much more and need to put large scale day to day. From the observation, it was seen that the administration provided two rupee coins to insert into the vendor if students did not have them themselves. Other 11.3 per cent did not like to respond to it.

Respondents were asked why others did not use the pads. Total 59.5 per cent of not using pad responded on it. Only 12.6 per cent told they had an allergic reaction. Similarly, 16.2 per cent told those pads were expensive. Likewise, 16.7 per cent felt discomfort and irritability. On the other hand, 11.7 per cent said it was difficult to dispose. Other 9 per cent said many responses like difficult to assess while needed.

Table 7

Time of Changing Pad

\begin{tabular}{ccc}
\hline Time of Changing Pad & Frequency & Per cent \\
\hline Once a day & 7 & 6.3 \\
Twice a day & 30 & 27.2 \\
Thrice a day & 32 & 29. \\
Whenever it wets & 41 & 37.2 \\
Total & 110 & 100 \\
\hline
\end{tabular}

Table 7 displays that more than one-third respondent 37.2 per cent changed sanitary pads whenever it wets. More than one quarter 29 per cent changed it thrice a day, 27.2 per cent changed twice a day. Only 6.3 changed once a day. Similarly, respondents were asked about their bathing. More than half 55 per cent told that they had bathed on the third day. Nearly one third 32.4 said they had to bathe daily. Similarly, 11.7 per cent told they bathe on the first day. One of the respondent said she did not bathe due to menstruation. Majhi (2016) found that only 22 per cent changed sanitary pads twice a day. Others changed only one in a day.

Table 8

Methods of Maintaining Menstrual Hygiene

\begin{tabular}{lccc}
\hline & Methods of Maintaining Menstrual Hygiene & Frequency & Per cent \\
\hline 1 & Bathing daily & 28 & 11.57 \\
2 & Time to time changing Pads & 52 & 21.48 \\
3 & Cleaning Genital and hand before changing Pad & 65 & 26.85 \\
4 & Both one and two & 27 & 11.15 \\
5 & Both two and three & 39 & 26.11 \\
6 & All one, two and Three & 31 & 12.80 \\
& Total & 242 & 100 \\
\hline
\end{tabular}

It was found that 11.57 per cent bathed daily. Similarly, 21.48 per cent changed pad from time to time. Likewise, 26.85 per cent cleaned genital and hand before changing pad. Only 11.65 per cent had a daily bath and frequent changing of pads. On the other hand, 26.11 per cent did both two and three. Nearly 13 per cent did all one to three. All one, two and three are good options to have good menstruation hygiene. Daily bath was restricted due to cultural taboos. Generally, the third day was the day of bathing. Majhi (2016) "Only 10 per cent of respondents bath daily though it is a good menstrual hygiene practice. More than one third 36 per cent of girls used ordinary soap 


\section{Knowledge and Practice of Menstrual Hygiene among the Girls}

and water to clean their vulva. More than one third 37 per cent of respondents did not wash their hands properly after using sanitary napkins during menstruation".

Table 9

Problems in the College during menstruation

\begin{tabular}{ccc}
\hline Problems in the College & Frequency & Per cent \\
\hline Disposal Bucket & 23 & 20.7 \\
Broken Doors & 4 & 3.6 \\
Water & 2 & 1.8 \\
Soap & 47 & 42.3 \\
Cultural Restriction & 2 & 1.8 \\
Others & 10 & 9.0 \\
No any Problems & 23 & 20.7 \\
Total & 111 & 100.0 \\
\hline
\end{tabular}

Table 9 displays that 20.7 per cent did not like to complain and thought all were good there in the college and a similar per cent complained that the problem is the disposal bucket. Only 3.6 per cent said that there were broken doors, 1.8 said there was water problem and cultural problems. Tripathi (2018) found that there was sufficient water in JMC as there is a system of lifting the underground water. All the rest rooms had good taping water. However, some students felt the problems of water when the tank of the top was lacking water. It might be happening if the electricity is off. More students $(42.3 \%)$ said that there was no soap in the wash bin. Similarly, nine per cent said that there were no utensils to collect water which is why they felt odd and difficult to wash the genitals.

Table 10

Problems at Home during menstruation

\begin{tabular}{llcc}
\hline & Problems at Home & Frequency & Per cent \\
\hline 1. & Entry into the Kitchen & 20 & 18.0 \\
2. & Unable to perform Puja & 60 & 54.1 \\
3. & Eating food like Cow Milk & 3 & 2.7 \\
4. & Sleeping on the same bed & 6 & 5.4 \\
5. & Both one and two & 12 & 10.8 \\
6. & Both two and four & 1 & 0.9 \\
7. & One, two and three & 1 & 2.7 \\
8. & One two and four & 5 & 0.9 \\
9. & All one to four & 111 & 4.5 \\
& $\quad$ Total & 100 \\
\hline
\end{tabular}

Table 10 shows that eighteen per cent had the problem of entry into the kitchen. The majority 54.1 per cent had the problem of performing puja. Only 2.7 could not use the same bed. Both one and two occurred 10.8 per cent. A few 5.4 per cent had no problems at their homes. It was found few Christian and Buddhist girls said they had no restrictions at their home during menstruation. In the case of Pokhara especially in JMC most of the girls were influenced by the culture of the Hindu religion. Even Buddhists and Christian said they had not to worship God and goddess while means. Majhi (2016) found that most girls did not attend any religious functions. More than half (57\%) of girls were not allowed to touch stored foods. More than two third (74\%) of girls were not allowed to touch plants during menstruation. 


\section{Knowledge and Practice of Menstrual Hygiene among the Girls}

\section{Conclusion}

Menstruation is a normal process of reproductive-age women. There might be some problems seen before and during the period. Menstrual hygiene is essential to prevent from more complex problems occurs in the future. Most of the girl students in college knew the knowledge and they had good practice on menstrual hygiene practice. More than two-third girls used sanitary pads available in the market. There was no significant relation among caste, type of family and use of absorbent because most girls were in homogenous group. It was concluded that peers were the influencing to use absorbent. Traditional beliefs in the society reflect on their behaviour such as bathing on third day, not to cook in the kitchen, deny visiting temple and performing Puja, drinking cow milk. Girl students should encourage applying safe and hygienic practices and hygienic behaviour. Multi-sectoral influence and awareness should be built to overcome the traditional health belief. Parents, social workers, teachers, students, health workers, Guru, Purohit, priests all should be made uniform to reduce such traditional unhygienic behaviour. Encourage the girls and women to make more hygiene during such a period such as daily bathe, changing pad and providing the skill and method of disposing of sanitary pads. All the Government and Non- Government Organizations need to work jointly to develop awareness among all stakeholders on personal hygiene during the menstruation period. Health education with the contents of reproductive health and sex education should be made mandatory to overcome such unhygienic behaviour. Menstrual hygiene contents should also be incorporated in the basic and secondary levels of the school curriculum.

\section{References}

Bhusal, C. K. (2020). Practice of menstrual hygiene and associated factors among adolescent school girls in Dang district, Nepal. Advances in Preventive Medicine 2020, 1292070. https://doi.org/10.1155/2020/1292070

Davis, C., P. (2019). Menstruation (menstrual cycle period). Medicine net.

Health line (June 14, 2012). Menstrual problems: Diagnosis, treatment, and outlook. https://www.healthline.com/health/menstrual-problems.

Jones, D.W. \& Bartlett, A. (June26, 2015). Women's Gynecologic Health. P. 94. ISBN 9780763756376.

Kamath, R., Ghosh, D., Lena, A. \& Chandrasekaran, K. (2013). A study on knowledge and practices regarding menstrual hygiene among rural and urban adolescent girls in Udupi Taluk, Manipal, India. Global Journal of Medicine and Public Health, 2(4).

Lawan, U. M., Yusuf, N., W., \& Musa, A., B. (2010). Menstruation and menstrual hygiene amongst adolescent school girls in Kano, Northwestern Nigeria. African Journal of Reproductive Health, 14(3), 201-207.

Majhi, S. (2016). A study on menstrual knowledge and practices among rural adolescent girls in burdwan district, West Bengal. International Journal of Advanced Research 4 (9): 896,902. https://doi.org/10.21474/IJAR01/1558

Moore, K. (June 18, 2020). Menstrual Problems. Medically reviewed by G. Nicolee. https: //www.healthline.com/health/menstrual-problems.

Singh, M., M., Devi, R., Garg, S., Mehra, M. (2001). Effectiveness of syndromic approach in management of reproductive tract infections in women. Indian $J$ Med Sci. 2001 April; 55(4):209-14. PMID: 11665391.

Teluram, P. R. (1978). Environmental health and hygiene. Vikas Publishing House. 


\section{Knowledge and Practice of Menstrual Hygiene among the Girls}

Tripathi, K., P. (2018) Students' perception towards the drinking water facility at Janapriya Multiple Campus, Pokhara", Janapriya Journal of Interdisciplinary Studies. Janapriya Multiple Campus.

Wash United (2020). Learn who is behind MH day and How can be a part of the MH day movement, as an organization, a supporter or individual. Menstrual Hygiene Day 2020. 